\title{
Hydrological Modelling and data assimilation of Satellite Snow Cover Area using a Land Surface Model, VIC
}

\author{
Shaini Naha ${ }^{\mathrm{a}}$, Praveen K Thakur ${ }^{\mathrm{b}}$ and S.P.Aggarwal ${ }^{\mathrm{c}}$ \\ a, b, Indian Institute of Remote Sensing Dehradun, \\ Email: $\underline{\text { shaininaha11@gmail.com }}$; praveen@iirs.gov.in ${ }^{\mathrm{b}} ; \underline{\text { spa@iirs.gov.in }}$
}

\section{Commission VIII, WG VIII/4}

\author{
Keywords: Snowmelt Runoff, Beas, VIC model, MODIS SCA, Data Assimilation, Direct Insertion, \\ Ensemble kalman filter (EnKF)
}

\begin{abstract}
The snow cover plays an important role in Himalayan region as it contributes a useful amount to the river discharge. So, besides estimating rainfall runoff, proper assessment of snowmelt runoff for efficient management and water resources planning is also required. A Land Surface Model, VIC (Variable Infiltration Capacity) is used at a high resolution grid size of $1 \mathrm{~km}$. Beas river basin up to Thalot in North West Himalayas $(\mathrm{NWH})$ have been selected as the study area. At first model setup is done and VIC has been run in its energy balance mode. The fluxes obtained from VIC has been routed to simulate the discharge for the time period of (2003-2006). Data Assimilation is done for the year 2006 and the techniques of Data Assimilation considered in this study are Direct Insertion (D.I) and Ensemble Kalman Filter (EnKF) that uses observations of snow covered area (SCA) to update hydrologic model states. The meteorological forcings were taken from $0.5 \mathrm{deg}$. resolution VIC global forcing data from 1979-2006 with daily maximum temperature, minimum temperature from Climate Research unit (CRU), rainfall from daily variability of NCEP and wind speed from NCEP-NCAR analysis as main inputs and Indian Meteorological Department (IMD) data of $0.25^{\circ}$. NBSSLUP soil map and land use land cover map of ISRO-GBP project for year 2014 were used for generating the soil parameters and vegetation parameters respectively. The threshold temperature i.e. the minimum rain temperature is $-0.5^{\circ} \mathrm{C}$ and maximum snow temperature is about $+0.5^{\circ} \mathrm{C}$ at which VIC can generate snow fluxes. Hydrological simulations were done using both NCEP and IMD based meteorological Forcing datasets, but very few snow fluxes were obtained using IMD data met forcing, whereas NCEP based met forcing has given significantly better snow fluxes throughout the simulation years as the temperature resolution as given by IMD data is $0.5^{\circ} \mathrm{C}$ and rainfall resolution of $0.25^{\circ} \mathrm{C}$. The simulated discharge has been validated using observed data from BBMB (Bhakra Beas Management Board) and coefficient of Correlation $\left(\mathrm{R}^{2}\right)$ measured for (2003-2006) was 0.67 and 0.61 for the year 2006.But as VIC does not consider snowmelt runoff as a part of the total discharge, snowmelt runoff has been estimated for the simulation both with and without D.A. The snow fluxes as generated from VIC gives basin average estimates of Snow Cover, SWE, Snow Depth and Snow melt. It has been observed to be overestimated when model predicted snow cover is compared with MODIS SCA of $500 \mathrm{~m}$ resolution from MOD10A2 for each year. So MODIS 8-day snow cover area has been assimilated directly into the model state as well as by using EnKF after every 8 days for the year 2006.D.I Technique performed well as compared to EnKF. R ${ }^{2}$ between Model SCA and MODIS SCA is estimated as 0.73 after D.I with Root Mean Square Error (RMSE) of +0.19 . After direct Insertion of D.A, SCA has been reduced comparatively which resulted in $7 \%$ reduction of annual snowmelt contribution to total discharge. The assimilation of MODIS SCA data hence improved the snow cover area (SCA) fraction and finally updated other snow components.
\end{abstract}

\section{INTRODUCTION}

Snow is one of the key environmental parameter which not only maintains the earth's radiation balance but also plays an important role in river discharge. So proper snowmelt studies is required for efficient management of water resources. Snow Cover Area (SCA), portion of the watershed covered by the snow is one of the vital parameter in terms of snowmelt runoff estimation. It forms a firm basis for improving other snow components i.e. Snow water equivalent (SWE), Snow depth and Snow Melt. Over the past two decades, Satellite remote sensing came into notice as the conventional methods of acquiring snow properties becomes very much difficult in inaccessible mountainous regions. It has opened the possibility of data acquisition at regular intervals, monitoring the existing conditions and also has been considered useful for several runoff forecasting and water management systems (Jain and Rathore, 2001). So this study aims at assimilating the MODIS snow cover product into an Energy balanced Land Surface model known as Variable Infiltration Capacity (VIC). This is known as Data Assimilation. There are many physically based hydrological model as well as Land Surface Models like SWAT, WinSRM , VIC, Noah LSM etc. SWAT partitions the rain and snow on the basis of temperature. WinSRM works on the Degree Day Approach and it divides the whole basin area into zones based on elevation and gives the snowmelt runoff but these models does not allow for Data Assimilation. This 
is the key reason of choosing VIC for this study. (Huang, 2012) used MODIS Snow cover fraction (SCF) to improve the Snow Water Equivalent (SWE), Snow Depth (SD) and Snow Melt(SM) by EnKF Technique of Data Assimilation. Validation of MODIS snow products and its very reasonably good agreement with the ground observation data from various regions are well known from the literatures of (Klein and Bernett, 2003); (Parajka and Bloeschl 2006); (Wang et al, 2008). (Jain et al, 2008) concluded that MODIS data could be effectively used for SCA estimation under Himalayan rugged topographic and harsh climatic conditions. Review of many other works also reveals how the MODIS snow-cover products have been used and also includes details regarding snow cover mapping accuracy. Though hydrologic remote sensing help in providing valuable information about Land Surface Conditions like SWE, SD, SM and soil moisture etc. but sometimes it may not be enough for many other applications. (Reichle et al, 2008) stated these data may be considered useful when used in Data Assimilation System. Direct Insertion is one of the earliest and most simplistic approaches to data assimilation where the forecast model states are directly replaced with the observations. This approach has been generally applied in many snow data assimilation studies (Reichle et al., 2008). (Rodell et al., 2004) have used direct insertion to assimilate MODIS snow cover observations into the Global Land Data Assimilation System (GLDAS). (Andreadis and Lettenmaier, 2005) have carried out snow data assimilation via an Ensemble Kalman Filter but slight improvement was noticed over the unupdated simulation. (Jin and Miller, 2003) also used this technique to study the snowpack impact on climate variability and snowmelt processes in mountainous regions. (McGuire et al., 2006) used VIC, a macroscale hydrological model in to adjust model's initial snow data using MODIS imagery for winters (2000-2004) and the insertion of the MODIS data resulted in forecast error reduction.

The current study uses the MODIS snow cover product (MOD10A2) to update the snow components by using a land surface hydrological model, VIC by applying the D.I and EnKF technique. The study also aims at estimating snowmelt runoff contribution to the annual discharge at the Thalot site. MOD10A2 comes in a spatial resolution of $500 * 500 \mathrm{~m}^{2}$ in every 8 -day period that begins on the first day of each year and extends to the first few days of the next year, (Maskey et al., 2011).

\section{STUDY AREA AND DATA USED}

The study area chosen for this work is Beas river basin in North West Himalaya (NWH). Beas River in northern India is an important river of Indus River system. It rises in the Himalayas in central Himachal Pradesh, India, and flows for some 470 kilometers to the Sutlej River in the Indian state of Punjab. Its total length is 470 kilometers and its drainage basin is 20,303 square kilometers. The Beas river basin with its outlet at Thalot discharge station is chosen for this study. It extends from $76.935-77.867^{\circ} \mathrm{E}$ and $31.507-32.414^{\circ} \mathrm{N}$. The basin covers an area of $4883 \mathrm{~km}^{2}$ out of which $70 \mathrm{~km}^{2}$ is under snow. The climate here varies with the elevation and is affected by the monsoon. The elevation of the basin till
Thalot extents from $938 \mathrm{~m}$ to $6500 \mathrm{~m}$ approximately where Rohtang covers the higher elevated area. The origin of higher streams and the Beas valley upstream to Kullu is the glaciated area of the basin. So, the discharge of the Beas River basin includes runoff from both melting of the snow and ice and the other resulting from the rainfall in the catchm

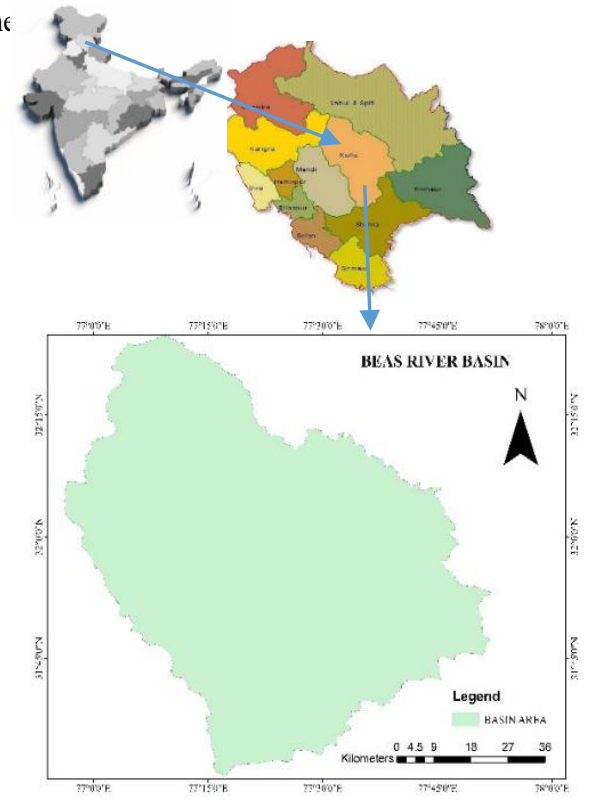

Figure 1. Study Area (Beas river basin)

The remote sensing data used in this study are 8-day $500 \mathrm{~m}$ resolution MODIS satellite Snow Cover Area data (MOD10A2 SCA product) for updating the model predicted fractional snow cover area. Other geo-spatial data such as Land Use Land Cover (LULC) map, DEM, soil map and the hydro-meteorological data has also been used. Cartosat Dem with resolution of 30 meters has been used for hydroprocessing and extraction of other topographic features like slope map, elevation zonal map, aspect map etc. The meteorological forcings were taken from $0.5 \mathrm{deg}$. resolution VIC global forcing data (Adam and Lettenmaier, 2003 and Adam et al., 2006) from 1979-2006 with daily maximum temperature, minimum temperature from Climate Research unit, rainfall from daily variability of NCEP and wind speed from NCEP-NCAR analysis as main inputs. This data has been downloaded from VIC website http://www.hydro.washington.edu/SurfaceWaterGroup/Dat a/met_global_0.5deg.html

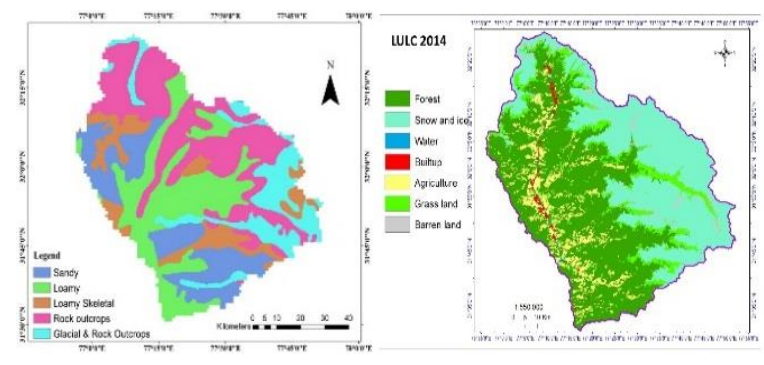

Figure 2.1. Soil Map (NBSS\&LUP), LULC map (2014) 


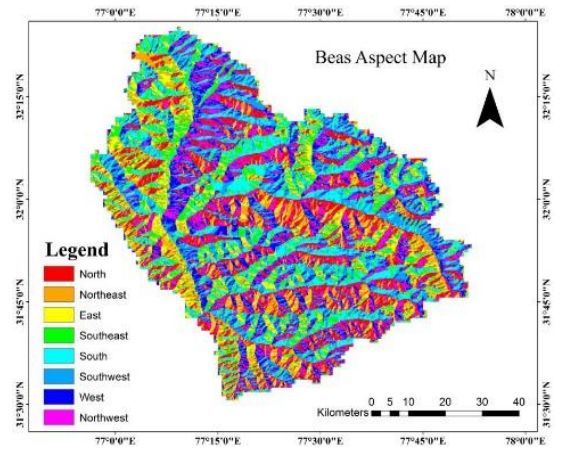

Figure 2.2. Beas Aspect Map

Indian Meteorological Department (IMD) data of $0.25^{\circ}$ were used for 2003-2006 time period and ERA-interim data, (Balsamo et al., 2012) has been used for the year 2006. The soil parameters has been generated using NBSSLUP soil map and vegetation parameters were generated using land use land cover maps of ISRO-GBP project for year 2014. Observed discharge data from Bhakra Beas Management Board (BBMB) has been used. These are all essential required inputs for running the VIC model.

\section{METHODOLOGY}

This study uses the land surface model Variable Infiltration Capacity (VIC) which solves both water balance and energy balance, Liang et al., (1994).This model accounts for the heterogeneity of the surface such as subgrid variability of vegetation classes, soil moisture storage capacity as it divides the whole study area into number of grids. Each grid can also be divided into different elevation zones that results in more realistic hydrology in mountainous regions. Study area has been divided into high grid resolution of $1 \mathrm{~km}(1 \mathrm{~km} *$ $1 \mathrm{~km}$ ). At first model setup is done and VIC has been run in its energy balance mode. The fluxes obtained from VIC has been routed to simulate the discharge for the time period of (2003-2006). Direct Insertion of Data Assimilation with SCA has been implemented for the year 2006 in this study to improve the model forecasts of other snow components. Keeping in view of other advanced Data Assimilation Techniques, Ensemble Kalman Filter has also been implemented.

\subsection{Methodology adopted for VIC model}

The watershed boundary is delineated from Cartosat DEM of 30 meters resolution and grids were generated over the basin area of high resolution of $1 \mathrm{~km}(0.01 * 0.01$ degree approx.). The soil parameter file generated from NBSSLUP describes the characteristics of each of the considered soil layer for each grid. Vegetation parameters are one of the important inputs in VIC model, being a physical based model, it requires numerous vegetation parameters. So, a vegetation parameter file containing the Land Use Land Cover properties of each grid cell has been prepared. VIC requires a minimum of three meteorological variables, Tmax- Daily maximum temperature (in ${ }^{\circ} \mathrm{C}$ ), Tmin- Daily minimum temperature $\left(\right.$ in ${ }^{\circ} \mathrm{C}$ ) and Precp- Daily precipitation (in $\mathrm{mm}$ ).A meteorological file was generated for each grid by using maximum and minimum temperature, precipitation, and wind speed.The threshold temperature i.e. the minimum rain temperature VIC can generate fluxes is $0.5^{\circ} \mathrm{C}$ and maximum snow temperature is about $+0.5^{\circ} \mathrm{C}$ at which VIC can generate snow fluxes. In this study minimum temperature at which rain can fall in liquid form is taken as $-0.5^{\circ} \mathrm{C}$ and maximum temperature at which snowfall can occur is taken as $+0.2^{\circ} \mathrm{C}$. Hydrological simulation has been done with all the meteorological forcing datasets mentioned above in Section 2. But the temperature resolution as given by IMD data is $0.5^{\circ} \mathrm{C}$ and rainfall resolution of $0.25^{\circ} \mathrm{C}$, so it generated very few snow fluxes. Hydrological simulation has also been done with ERA-interim data for the year 2006.

Since VIC considers each grid cell to be flat, this assumption lead to improper snowmelt estimation in mountainous regions. So an elevation band text file has been prepared which gives information about mean elevation of each grid and fractional area covered by each elevation zone in each grid. For, this DEM has been reclassified into 10 elevation classes ranging from $938 \mathrm{~m}$ to $6500 \mathrm{~m}$. Zone wise fractional area for each grid cell has been calculated from the tabulate area tool in Arc GIs, then by performing union between reclassify vector DEM and grid file, zonal statistics between union file and DEM mean elevation value for each zone in each grid is calculated. A global parameter file was generated by the VIC Model. The parameter file contains the user preferences and the parameters that have been prepared, including information about the number of layers, time step, location of the input and the output files and the modes which are to be activated.

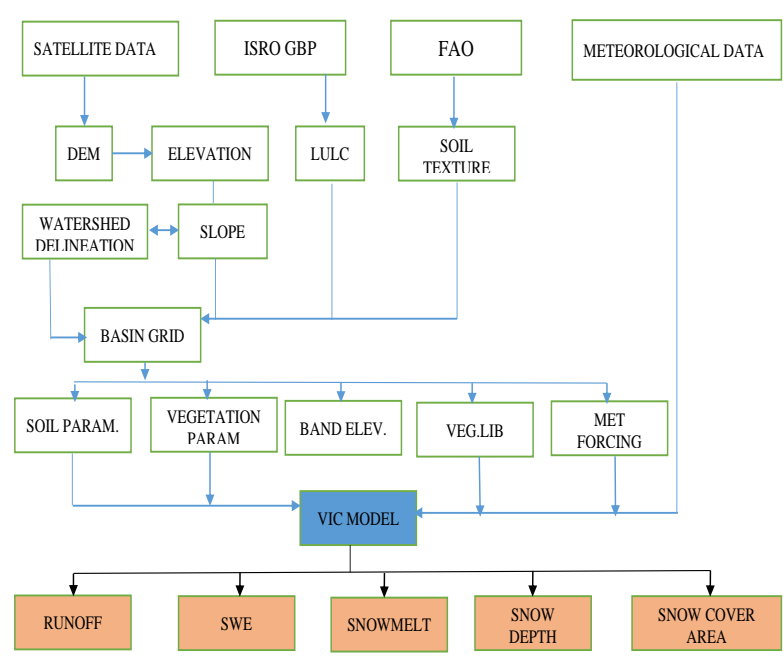

Figure 3.1. Overall Methodology

The VIC files were first prepared by the VIC tool and once the input files were ready, the model has been run for the time period of 2003-2006. Then routing files has been prepared which includes fraction file, station file, flow direction file and the unit hydrograph file. The fraction file 
provides the VIC routing model (Lohmann et al, 1996) the fraction of each grid cell in the study area and the station file provides the exact position of the outlet. Flow direction file shows flow direction value for each grid cell in the format of VIC. Finally, the water and energy balance components which were obtained from the VIC fluxes has been routed to get the discharge.

\subsection{Assimilation Method}

Direct Insertion approach has been used in this study which is the earliest and simplest method for the Data Assimilation. MODIS Relative daily snow cover areas for the year 2006 were derived from MOD10A2 8 day's composite snow cover data. These snow products are geocoded gridded products covering large areas, therefore boundary of study area map was used to subset them to get basin wise SCA maps which contained areas of snow ,non-snow and cloud. Based on snow line elevation, cloud cover has been removed. Then the MODIS snow cover extent observations are directly inserted into the model inputs. This method clearly assumes that the observation data are more useful than the model predicted results. To, test the effect of assimilation of fractional snow cover area in hydrological model, this approach has been implemented on Beas river basin of NWH. At first VIC model has been run for 1 st 8 days of 2006, fluxes are generated for 8 days, along with that, a model state file is generated by the VIC model for a particular day i.e. 8th day. Similarly MODIS SCA is available for that particular day. Then the fractional snow cover area given by MODIS is directly replaced in the model state file. Then again the model has been run for the next eight days. The process continues so on. Keeping in view the disadvantages of Direct Insertion Technique of D.A, Ensemble Kalman Filter has also been used. As D.I Technique disregards both important imformation provided by the model and the satellite, and only preserves the observational errors, EnKF becomes advantageous in this case. EnKF first described by (Evensen, 1994) who gives the idea to use kalman filter for the non-linear systems by using ensembles or statistical examples of the forecasted model states. In the forecast step, the ensemble members are each forecast individually by the full non linear model, and in the analysis step the update equations are based on the linear equations used in the kalman filter.

The main Equation of the Ensemble Kalman Filter is given below:

$\mathrm{X}_{\mathrm{i}}^{\mathrm{a}}=\mathrm{X}_{\mathrm{i}}^{\mathrm{b}}+\mathrm{K}\left(\mathrm{Y}-\mathrm{H}\left(\mathrm{X}_{\mathrm{i}}^{\mathrm{b}}\right)\right)$

$\mathrm{K}=\mathrm{P}^{\mathrm{b}} \mathrm{H}^{\mathrm{T}}\left(\mathrm{HP} \mathrm{P}^{\mathrm{b}} \mathrm{H}^{\mathrm{T}}+\mathrm{R}\right)^{-1}$

$\mathrm{P}^{\mathrm{b}}=1 /(\mathrm{N}-1) \mathrm{X}_{\mathrm{i}}^{\mathrm{b}}\left(\mathrm{X}_{\mathrm{i}}^{\mathrm{b}}\right)^{\mathrm{T}}$

$\mathrm{X}^{\mathrm{a}}=$ updated estimate of the analyzed state. $\left(\mathrm{N}^{*} 1\right)$

$\mathrm{X}^{\mathrm{b}}=$ background Model forecast $\left(\mathrm{N}^{*} 1\right)$

$\mathrm{I}=1$ to $\mathrm{N}$, where $\mathrm{N}$ is the number of ensembles

$\mathrm{Y}=$ Observations $\left(\mathrm{Y}^{*} 1\right)$

$\mathrm{H}=$ Observation operator that converts the states in the model into observation space

$\mathrm{K}=$ Kalman gain that weighs the effect of the observations to the state update

$\mathrm{R}=$ Observation error covariance with dimension $(\mathrm{P} * \mathrm{P})$

$\mathrm{P}^{\mathrm{b}=}$ Background error covariance $(\mathrm{P} * \mathrm{P})$

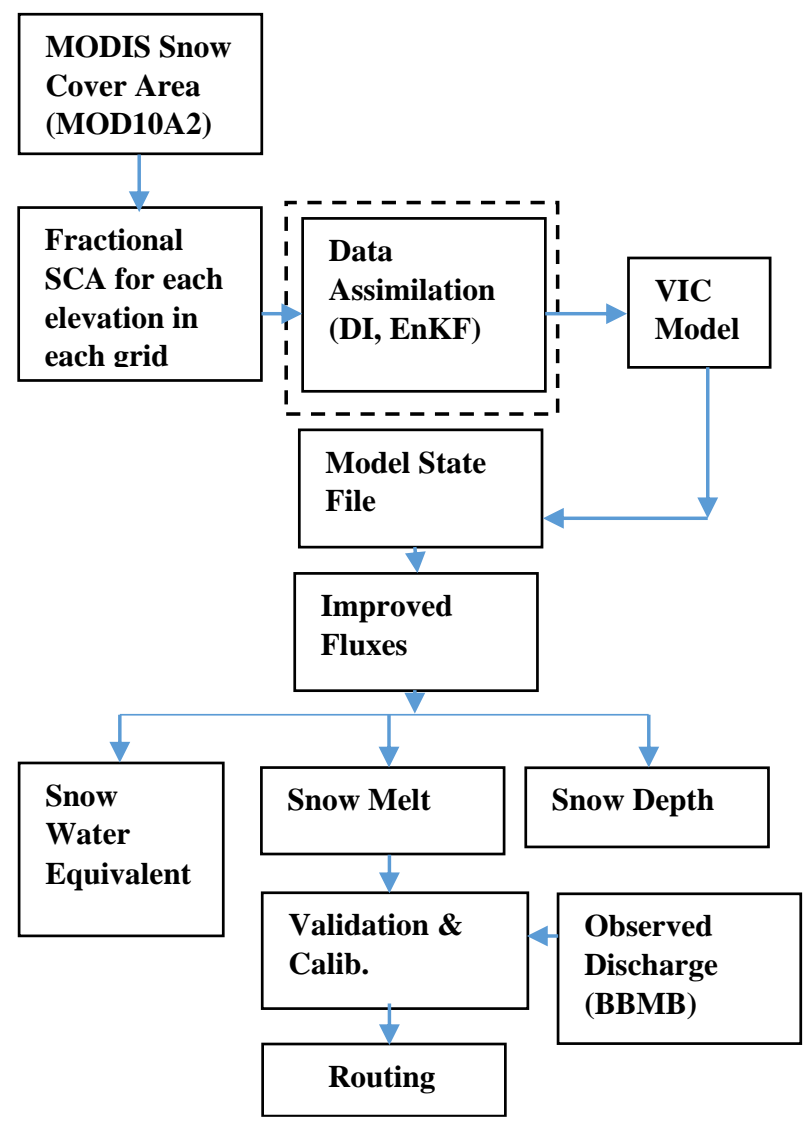

Figure 3.2. Data Assimilation flow chart

In this study the observation operator was considered to be 1 as both the observation and model parameter were same i.e. Snow cover fractional area.

\section{RESULTS AND DISCUSSIONS}

\subsection{Model (VIC) Results}

VIC has been run for consecutive four years (2003-2006) and routing has been done for the same. Coefficient of Correlation $\left(\mathrm{R}^{2}\right)$ as compared with the observed discharge data from Thalot for these four years is 0.65 . But VIC does not consider snowmelt runoff while routing discharge, rather only considers the runoff (surface water) that has entered the local stream channel. So, in order to differentiate the rainfall runoff and snowmelt runoff, Jain et al (2015) used the method as follows.

Runoff $_{\text {snowmelt } i}=\min \left(\right.$ Runoff $_{\text {total }_{i}} *\left[\right.$ Melt $_{\mathrm{i}} /\left(\right.$ Rain $_{\mathrm{i}}+$ Melt $\left.\left._{\mathrm{i}}\right)\right]$, Melt ${ }_{\text {i) }} \mathrm{mm} / \mathrm{month}$

Same formula has been used in this study and contribution of snowmelt runoff to total discharge for the melt period (March-May) has been estimated has $35.3 \%$ for the whole 
basin. Annual contribution of snowmelt runoff to total discharge is calculated as $20.21 \%$. Figure 4.1 shows spatial maps of some hydrological components for the simulated period.

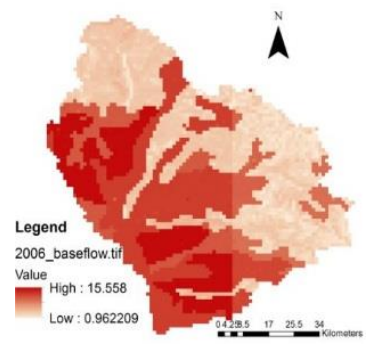

Baseflow(2006)

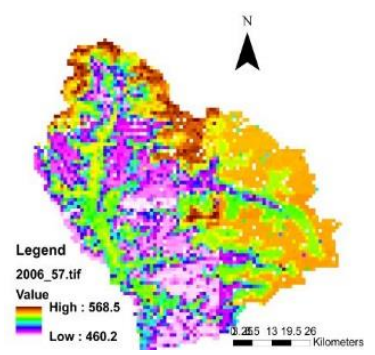

SWE $\left(2006,26^{\text {th }} \mathrm{Feb}\right)$

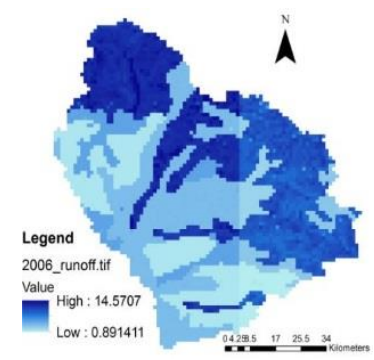

Runoff(2006)

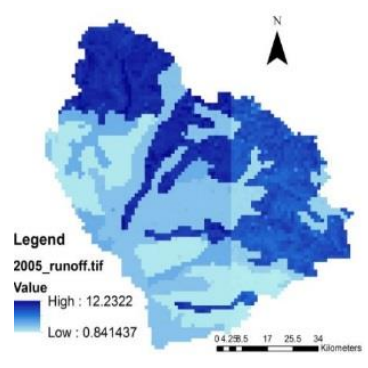

Runoff (2005)
Figure 4.1. Simulated Water balance components

Basin wise annual mean results computed from the snow fluxes for four consecutive years as obtained by VIC by using the NCEP data are shown below.

VIC simulated snow cover fractions are overestimated when compared with 8-day $500 \mathrm{~m}$ resolution MODIS satellite Snow Cover Area data which gives average snow cover fraction as about 0.42 for the same four years. According to (Sheffield et al., 2003), the VIC model uses both the subgrid vegetation tiling and elevation banding and clearly assumes snow cover if Snow Water Equivalent is present in that grid otherwise snow cover is considered to be Zero.

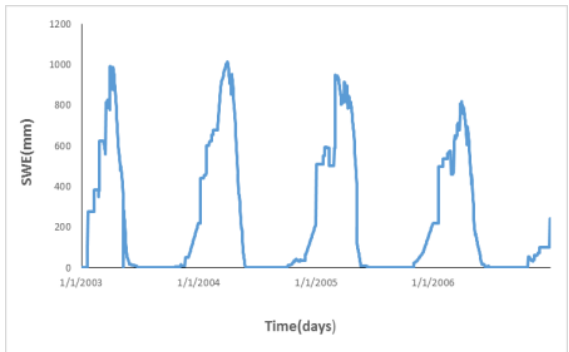

Figure 4.2. Snow Water Equivalent (2003-2006) (VIC)

It was needed to validate the VIC based snow cover with MODIS SCA. We can clearly see that VIC predicts full snow till the month of August whereas snow starts melting from the middle of May in case of MODIS. $\mathrm{R}^{2}$ measured is 0.61 with Root Mean Squared Error (RMSE) of 0.25 for the year 2006. As the melting of snow is directly proportional to the temperature, VIC global meteorological forcing were validated with ERA Interim data (Balsamo et al., 2012) and
IMD data (Srivastava et al., 2008) in the first part of this paper by (Thakur et al., 2016). It was found that VIC global data at 0.5 deg., resolution has low values of T-max, T-min and very high values of rainfall as compared to ERA-interim will certainly not cause any snowfall(Figure 4.5).

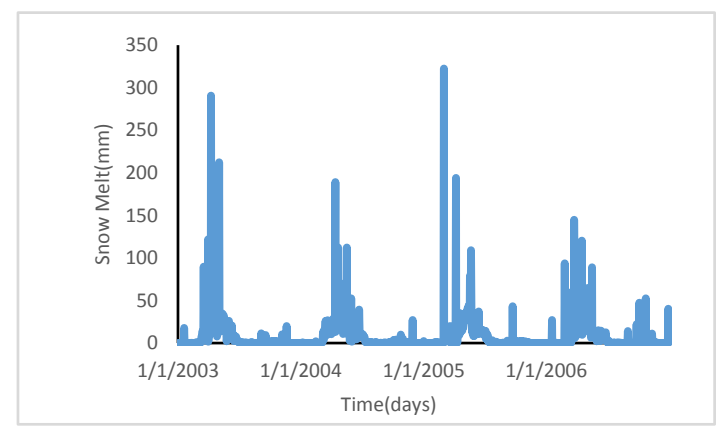

Figure 4.3. Snow Melt (2003-2006) (VIC)

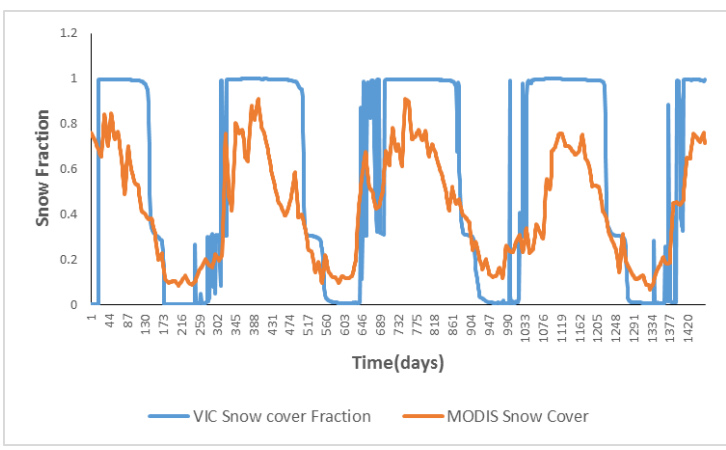

Figure 4.4. Snow Cover Comparison (2003-2006)

As we can see from Figure 4.6, ERA Interim rainfall has been underestimated the rainfall for the year 2006. Therefore keeping in view these merits and demerits of the datasets this study used the VIC global Meteorological Forcings. But due to low T-max, T-min and very high rainfall, SCA has been overestimated in VIC model and due to this, other snow components are also wrongly interpreted in some cases. So there is a need of Data Assimilation.

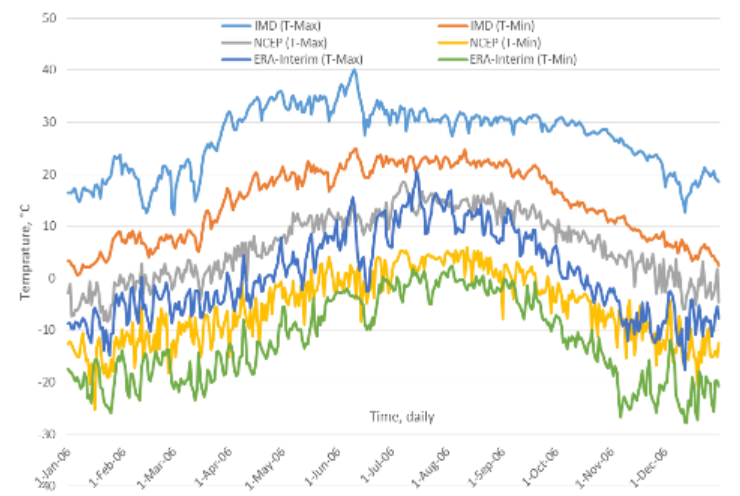

Figure 4.5. Comparison of temperature data sources for year 2006 (IMD, VIC-global \& ERA-Interim) for entire Beas basin. 
VIC has also been run using ERA-interim once for the year 2006 to compare SCA with the original simulated SCA as well as after D.A. $\mathrm{R}^{2}$ between SCA from ERA-interim and original MODIS SCA is 0.71 and RMSE of $+0.13(13 \%$ SCA).Though the trend is better than that simulated by D.I and EnKF technique, still there is a scope for Data Assimilation.

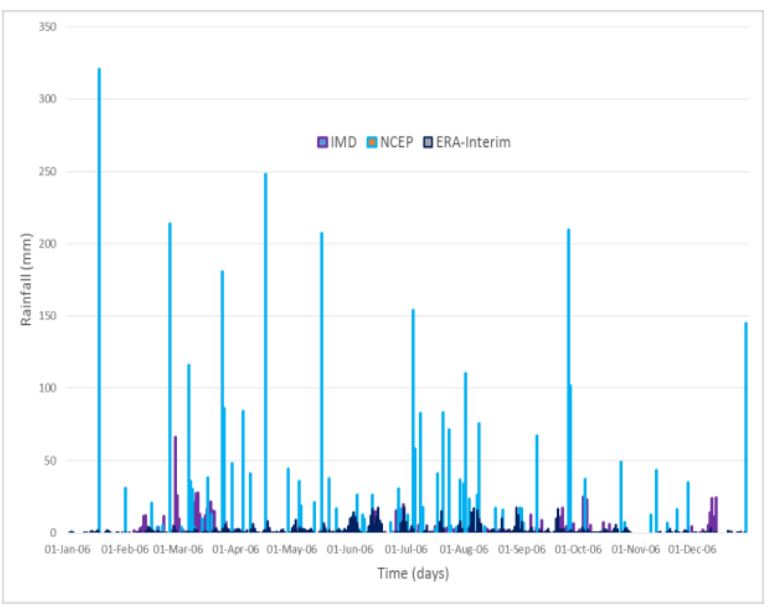

Figure 4.6. Comparison of rainfall data sources for year 2006 (IMD, VIC-global and ERA-Interim) for entire Beas basin

\subsection{Data Assimilation Results}

In order to improve the simulated snow water equivalent,snow depth and snow melt and river flow, MODIS snow cover fraction has been directly inserted into the model state file and also has been inserted using the EnKF technique as explained in Eq 1,2,3. 8-day $500 \mathrm{~m}$ resolution MODIS SCA data has been resampled into $1 \mathrm{~km}$ Cloud cover has been removed and SCA has been modified using the snow line elevation. Figure 4.10 shows the MODIS SCA for the same time period which has been assimilated in the model to mark the changes. The impact of assimilating MODIS data on the SCE of the basin for 2006 with the D.I technique has been examined first. The snow cover starts declining from the month of May which has updated the SWE in a consistent manner if compared with MODIS SCA. The Figures below shows comparison of the snow components before and after Direct Insertion. As can be seen from Figure 4.8 maximum snow occurs in the end of January to the middle of February hence two peaks of SWE can also be seen at that time. But in the original simulation a shift in the SWE peak is noted which is in the month of April. Enkf propagates through the errors of both model and Satellite observation so during the start of the simulation period, SWE values $(300 \mathrm{~mm})$ seems to lie in between original simulation $(200 \mathrm{~mm})$ and that of D.I $(480 \mathrm{~mm})$. This trend continues till the month of march and after that it becomes less than that of simulated from D.I. The snow melt when compared with the snow cover curve as shown in Figure 4.10 shows that the melting of snow well corresponds to the snow cover after both the assimilations (DI \& Enkf) compared to the original simulation. It has been well observed that from the end of February to march, there is a sudden increase in Snow melt after assimilation which is quite satisfactory if the MODIS

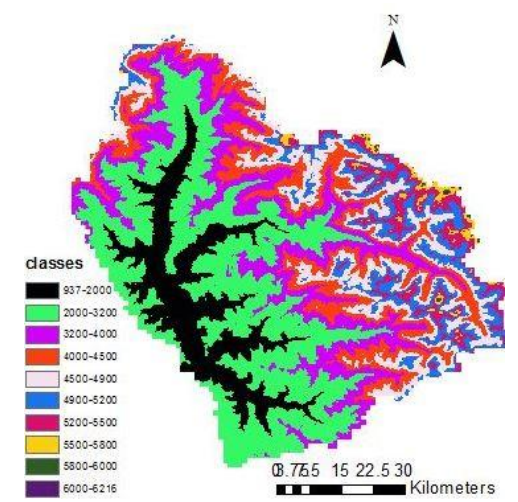

Figure 4.7 Elevation Zonal Map

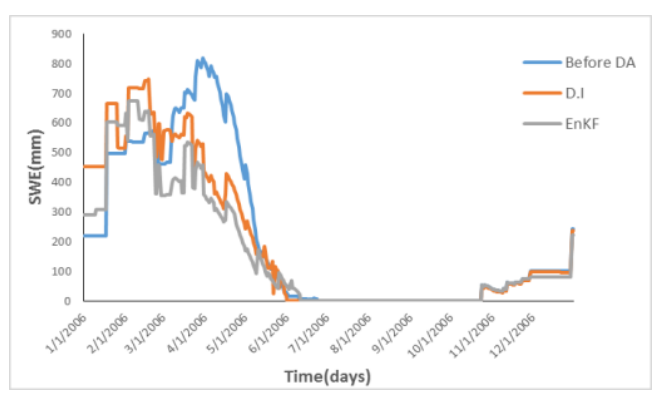

Figure 4.8. SWE comparison (2006)

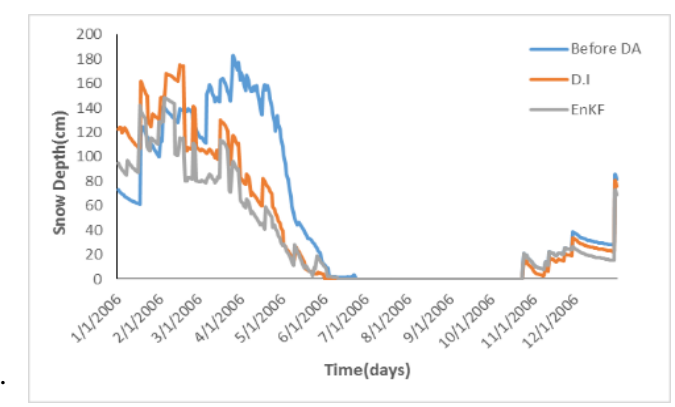

Figure 4.9. Snow Depth comparison (2006)

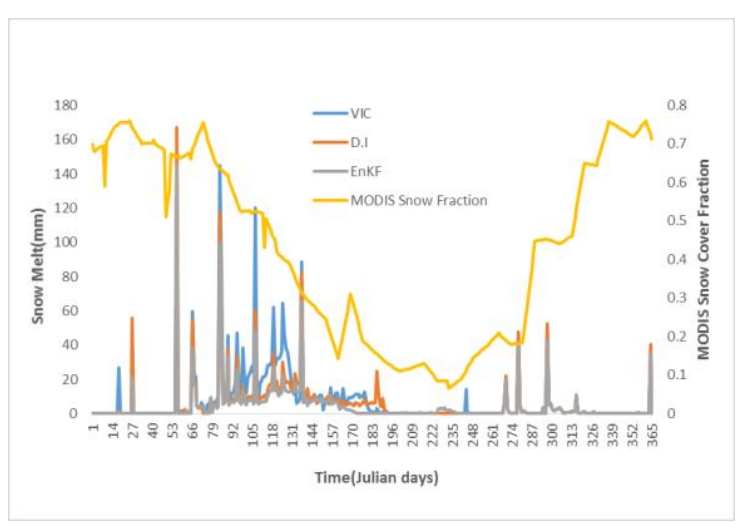

Figure 4.10 Snow Melt Comparison

SCA is observed at that time as well as the snow water equivalent in Figure 4.10. When the snow cover starts declining in the middle of March,Snow melt has also decreased a bit after D.A. As in Figure 4.11 Snow Cover reaches the minimum value in the month of August whereas 
it starts declining from the start of May and finally becomes Zero in the month of June in case of D.I. The D.I technique updated the snow cover in a more consistent manner as compared to EnKF if the original snow cover pattern is observed.

$\mathrm{R}^{2}$ between MODIS and VIC based SCA after DI is 0.73 with RMSE of $+0.194(19.4 \%)$ as compared to MODIS and original VIC based SCA which resulted in $\mathrm{R}^{2}$ of 0.58 and RMSE of 0.29 (29\% SCA). Next $\mathrm{R}^{2}$ between MODIS SCA and VIC after applying EnKF is 0.76 but it resulted in more RMSE of $+0.231(23 \%)$. $\mathrm{R}^{2}$ in case of D.I is still high but as it resulted in reduction of $10 \%$ error, it is considered to be a better approach for this study as compared to EnKF.

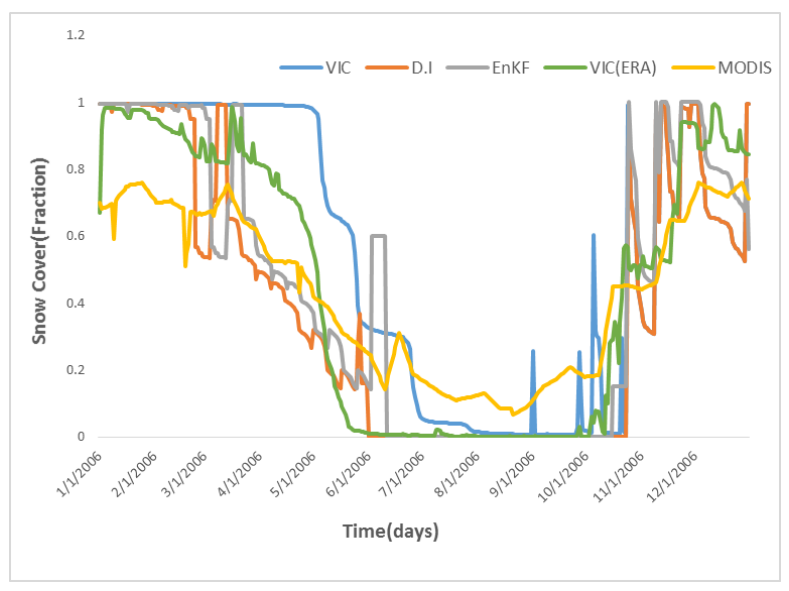

Figure 4.11 Snow Cover Comparison (2006)

\subsection{Validation after data assimilation}

Some spatial maps has been shown to better interpret and compare the VIC simulated Snow components after Assimilation with actual MODIS SCA. It can be well correlated if the Spatial maps of SWE before DA (Figure 4.12,4.13) and the Elevation zone file (Figure 4.7) is observed.The snow and non snow areas has been well partitioned after D.A.But some snow covered areas are not well updated according to the elevation zones as the maximum SWE should be present in the higher elevation zones. $\mathrm{R}^{2}$ as measured for river discharge of Beas Basin for VIC simulation for the year 2006 is 0.66.After Direct Insertion $\mathrm{R}^{2}$ is 0.74 .

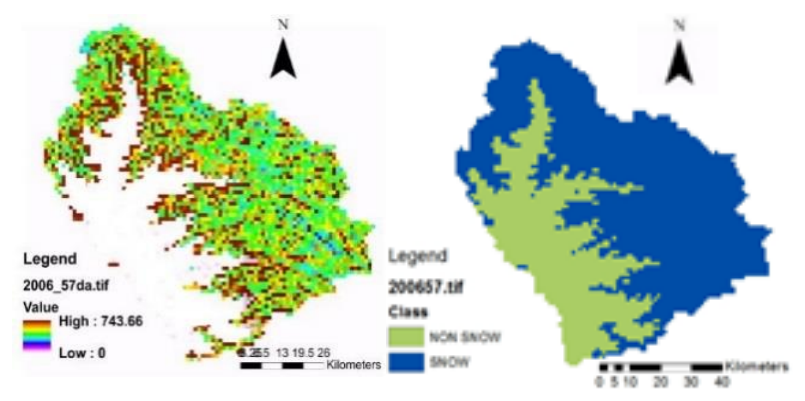

Figure 4.12. SWE $\left(26^{\text {th }} \mathrm{Feb}\right)$
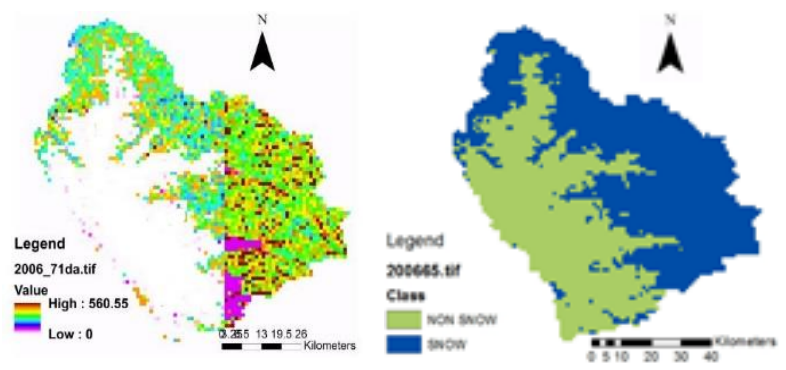

Figure 4.13. SWE (12 ${ }^{\text {th }}$ Mar) Snow Cover $\left(12^{\text {th }}\right.$ Mar $)$

Similarly snowmelt runoff contribution to the total runoff has been estimated using equation 4 given in sub-section 4.1 . $26.3 \%$ of total runoff has been contributed by the snowmelt runoff in the melt period (Mar-May) whereas annual contribution of snowmelt runoff to total discharge is calculated as $14.21 \%$ for the whole basin. In case of original simulation overestimation of SCA led to more contribution of snowmelt runoff to the total discharge. After direct Insertion of D.A, SCA has been reduced comparatively which resulted in $7 \%$ and $8.9 \%$ reduction of annual snowmelt contribution to total discharge in the melt season and throughout the year respectively at Thalot site. Maximum and minimum snowmelt contribution has been observed in the month of April (30.21\%) and August $(1.31 \%)$ respectively after D.A. After adding the snowmelt runoff to the simulated discharge, $\mathrm{R}^{2}$ between observed and simulated discharge before D.A is calculated as $0.29 . \mathrm{R}^{2}$ increased to 0.4 after D.I of Data Assimilation.

\section{CONCLUSION AND RECOMMENDATION}

Energy balanced Hydrological Modelling and two different techniques for assimilating fractional snow cover area in a Land Surface Model has been presented. The assimilation methods once used MODIS SCA directly into the model and then in an ensemble Kalman filter to alter the sub-grid variability of SWE, Snow Depth (S.D) and Snow Melt (S.M). It was well demonstrated from the graphical representations and the spatial maps that assimilating SCA information with D.I effectively modifies the sub-grid distribution of SWE, S.D, S.M and also modified the simulation of streamflow better than EnKF.

Although VIC is able to simulate all the water budget and energy balance components but inaccuracy and uncertainty of input meteorological forcing data directly affects its hydrological and snow outputs such as runoff, base flow, snow depth, SCA and SWE. Although SWE has been updated well for the snow free areas (Figure 4.14, 4.15) after D.I but inaccuracy still lies in snow fed areas where SWE should directly vary with the elevation. At some days the model detects more snow in the lower elevation than the higher elevated areas. These are mainly due to the meteorological datasets used. So, VIC global Meteorological Forcing data should be used with caution in head water river basins of Himalayas, where snow and glacier dominates the overall hydrology of basin.(Thakur et al.,2016).Simulation has been done with ERA-interim for 2006 to avoid the over estimation of SCA. But there is also a need for Data Assimilation as at some places SCA is 
overestimated and at some, underestimated (Figure 4.11). Another area which needs attention is the Data Assimilation Techniques. May be in case of proper meteorological datasets used, EnKF may become an effective feasible solution for improving snow properties prediction. There are also many advanced techniques available such as Extended Kalman Filter, 3D/4D Variance etc. which should be looked upon too.Apart from SCA validation, Snow Depth, SWE shall also be validated.

\section{ACKNOWLEDGEMENTS}

Authors acknowledge the support from Director, Indian Institute of Remote Sensing (IIRS) and Director, Snow and Avalanche Studies Establishment (SASE) for their valuable suggestions and support to complete this research work. This work is done as a part of M.Tech Thesis under project fellowship from Indian Institute of Remote Sensing, ISRO on "Ensemble Prediction and Data Assimilation for Hydrological Modelling of Beas river basin." Satellite data of MODIS SCA product was download from National Snow and Ice Data Centre (NSIDC).VIC global data was taken from VIC-University of Washington website.

\section{REFERENCES}

Adam, J.C. and Lettenmaier, D.P., 2003. Adjustment of global gridded precipitation for systematic bias, J. Geophys. Res., 108(D9), pp. 1-14.

Adam, J.C., Clark, E.A., Lettenmaier, D.P. and Wood, E.F., 2006. Correction of Global Precipitation Products for Orographic Effects, J. Clim., 19(1), pp. 15-38.

Andreadis, K. M., \& Lettenmaier, D. P. (2006). Assimilating remotely sensed snow observations into a macroscale hydrology model. Advances in Water Resources, 29(6), 872886.

Balsamo, G., Albergel, C., Beljaars, A.C.M., Boussetta, S., Brun, E., Cloke, H.L., Dee, D.P., Dutra, E., Pappenberger, F., De Rosnay, P., Sabater, J.M., Stockdale, T. and Vitart, F., 2012. ERA-Interim/Land: A global land-surface reanalysis based on ERA-Interim meteorological forcing, ERA Report Series no 13, ECMWF, 25 pp.

Evensen, G. (1994). Sequential data assimilation with a nonlinear quasi-geostrophic model using Monte Carlo methods to forecast error statistics. Journal of Geophysical Research: Oceans, 99(C5), 10143-10162.

Huang, C. (2012, October). Assimilation of MODIS snow cover fraction for improving snow variables estimation in west China. In SPIE Remote Sensing (pp. 853111-853111). International Society for Optics and Photonics.

Jain, S. K., Goswami, A., and Saraf, A. K., 2008. Accuracy assessment of MODIS, NOAA and IRS data in snow cover mapping under Himalayan conditions. International Journal of Remote Sensing, 29(20), 5863-5878.

Jain, S. K., Rathore, D. S., \& Chaudhary, A. (2001). Snow cover estimation in Himalayan basins using remote sensing. A Report by the National Institute of Hydrology, Roorkee.
Jain, S., (2015). Hydrological modelling for Ganga basin with focus on snowmelt runoff, Master of Technology thesis in Remote Sensing and GIS, Andhra University, Visakhapatnam, conducted at Water Resources Department (WRD), Indian Institute of Remote Sensing (IIRS), 70 pp, http://www.iirs.gov.in/iirs/sites/default/files/StudentThesis/ SUKANT\%20JAIN MTech 2013-15.pdf, accessed on 02 Apr. 2016.

Jin, J., \& Miller, N. L. (2004). An analysis of climate variability and snowmelt mechanisms in mountainous regions. Journal of Hydrometeorology. (Submitted).

Klein, A. G., \& Barnett, A. C. (2003). Validation of daily MODIS snow cover maps of the Upper Rio Grande River Basin for the 2000-2001 snow year. Remote Sensing of Environment, 86(2), 162-176.

Liang, X., et al. (1994), a simple hydrologically based model of land-surface water and energy fluxes for generalcirculation models, J. Geophys. Res.-Atmos., 99(D7), 1441514428.

Lohmann, D., NOLTE-HOLUBE, R. A. L. P. H., \& Raschke, E. (1996). A large-scale horizontal routing model to be coupled to land surface parametrization schemes. Tellus A, 48(5), 708-721.

Maskey, S., Uhlenbrook, S., \& Ojha, S. (2011). An analysis of snow cover changes in the Himalayan region using MODIS snow products and in-situ temperature data. Climatic Change, 108(1-2), 391-400.

McGuire, M., Wood, A. W., Hamlet, A. F., \& Lettenmaier, D. P. (2006). Use of satellite data for streamflow and reservoir storage forecasts in the Snake River Basin. Journal of Water Resources Planning and Management, 132(2), 97110.

Parajka, J., \& Blöschl, G. (2006). Validation of MODIS snow cover images over Austria. Hydrology and Earth System Sciences Discussions Discussions, 3(4), 1569-1601.

Reichle, R. H., Crow, W. T., \& Keppenne, C. L. (2008). An adaptive ensemble Kalman filter for soil moisture data assimilation. Water resources research, 44(3).

Rodell, M., \& Houser, P. R. (2004). Updating a land surface model with MODIS-derived snow cover. Journal of Hydrometeorology, 5(6), 1064-1075.

Sheffield, J., Pan, M., Wood, E. F., Mitchell, K.E., Houser, P.R., Schaake, J.C., Robock, A., Lohmann, D., Cosgrove, B., Duan, Q., Luo, L., Higgins, R.W., Pinker, R.T., Tarpley, J. D. Ramsay, B.H., 2003. Snow Process Modeling in the North American Land Data Assimilation System (NLDAS). Part I: Evaluation of Model Simulated Snow Cover Extent, Journal of geophysical research, 108, NO. D22, 8849.

Thakur, P.K., Aggarwal, S.P., Garg, V., Soni, C., Arun, Snehmani, (2016). Abstract accepted for XXIII ISPRS Congress, Prague, July 12-16, 2016.

Wang, X., Xie, H., \& Liang, T., 2008. Evaluation of MODIS snow cover and cloud mask and its application in Northern Xinjiang, China. Remote Sensing of Environment, 112(4), 1497-1513. 